\title{
ИННОВАЦИИ
}

УДК 330.34

DOI 10.17223/19988648/33/7

\section{А.Г. Шумилин}

\section{СУЩНОСТЬ И ФУНКЦИИ НАЦИОНАЛЬНОЙ ИННОВАЦИОННОЙ СИСТЕМЫ}

\begin{abstract}
В статье рассматривается развитие методологических основ «национальной инновационной системы» (НИС), приводится критический анализ взглядов американских, английских, иведских, российских и белорусских ученых на ее сущность и дается авторская трактовка данной категории. Исследуется взаимосвязь и взаимовлияние между элементами НИС. На основе анализа НИС выделены три методологические функции, предлагается авторский подход к определению функций НИС, а также выделены и раскрыты восемь основных функций системы.

Ключевые слова: национальная инновационная система, функции системы, элементы системы, развитие, рынок.
\end{abstract}

Начало разработки методологических основ «национальной инновационной системы» (НИС) относится к середине 1980-х гг. В это время в мировой экономике было завершено формирование четвертого технологического уклада и начался период становления пятого. В развитых странах к этому периоду, по мнению С.Ю. Глазьева, уже сложились основные механизмы инновационной деятельности и началась их унификация [2].

Теорию формирования НИС первыми стали исследовать К. Фриман (Великобритания), Б.-А. Лундвалл (Швеция) и Р. Нильсон (США) [7]. Они провели анализ развития инновационной деятельности в разных странах и теоретически обобщили процессы обновления.

К. Фриман определил НИС как сеть государственных институтов и частных формирований, осуществляющих деятельность и взаимодействие по инициации, импорту, модификации и распространению новых технологий. Иными словами, в основу инновационной системы им были положены новые технологии.

К. Фриман исследовал институциональный элемент инновационной деятельности. Он рассматривал экономики развитых стран, показавших высокий экономический рост благодаря развитию науки, образования и наукоемкой промышленности.

Б.-А. Лундвалл рассматривал НИС как элементы и взаимосвязи, находящиеся в границах государства и действующие в процессе получения, распространения и использования нового экономически выгодного знания. То есть, по его мнению, основой инноваций как системы являются новые знания, которые можно выгодно применить в экономике. 
Б.-А Лундвалл исследовал взаимоотношения между производителями и потребителями новых знаний и инновационных технологий. Круг его исследований охватывает страны Северной Европы.

Р. Нельсон считал, что НИС есть набор организаций, чье взаимодействие определяет инновационное развитие национальных фирм. Можно сказать, что главным элементом инновационной системы он определил комплекс организационных институтов.

Р. Нельсон исследовал пути формирования государственной научнотехнической политики. На основе сравнения опыта разных стран он показал, что рыночные механизмы наиболее эффективны и в инновационной деятельности.

Итак, К. Фриман, Б.-А. Лундвалл и Р. Нельсон оказались на разных позициях в определении главного звена национальной инновационной системы, а именно: новые технологии, новые знания, организационные институты.

Некоторым образом «примирить» эти три позиции несколько позднее попытался Меткалф. Он определил НИС как систему организаций, взаимодействующих для создания, сохранения и передачи знаний, навыков и изделий на основе новых технологий [3. С. 33].

Однако единые подходы к определению сущности НИС так и не были сформулированы даже для стран с рыночной экономикой, обладающих высоким научным потенциалом и развитой наукоемкой промышленностью.

В основу теории национальных инновационных систем целесообразно положить более ранние экономические разработки, а именно: теорию экономической динамики Шумпетера, институциональную теорию Норта, теорию рассеянного знания Хайека, концепцию роли научно-технологического процесса в экономическом росте Солоу, новую теорию роста Ромера и Лукаса. На их основании, а также с учетом анализа эволюции теоретических основ инновационных систем стало возможным установить главные методологические принципы теории НИС. Можно выделить три принципа:

- конкуренция на основе инноваций и научных исследований на производстве есть главный фактор экономической динамики;

- на содержание и структуру инновационной деятельности можно активно влиять посредством организационных институтов;

- новое знание играет особую роль в экономическом развитии.

Теорию национальных инновационных систем активно исследовали и ряд российских ученых: В.А. Васин, В.В. Иванов, Н.И. Иванова, Л.Э. Миндели и др. $[1,3,4]$. Они расследуют свои определения сущности национальной инновационной системы.

Так, В.В. Иванов предлагает определить «НИС как федеральнорегиональную систему, являющуюся составной частью экономики государства (союза государств) и представляющую собой совокупность хозяйствующих субъектов, взаимодействующих в процессе производства, распространения и использования нового экономически выгодного знания, направления деятельности которой определяются проводимой макроэкономической политикой и регулируются соответствующей нормативной правовой базой» [1. C. 33-34]. 
Из этого объемного определения вытекает, что целью НИС является поддержание устойчивого развития экономики на основе распространения и реализации новых знаний, т.е. использование интеллектуального потенциала нации в экономическом прогрессе. Успешность деятельности НИС будет зависеть от инновационной политики, эффективности управления, наличия ясных стимулов для развития науки и образования, наукоемкой крупной промышленности и малого предпринимательства.

В определении сущности НИС мы исходим из системных характеристик этого явления: множественности элементов, их взаимовлияния и взаимозависимости, новых системных качеств. Национальный же аспект определяется границами государства, в которых происходит его деятельность и осуществляется системное влияние.

Элементами НИС выступают научные институты и центры, образовательные учреждения, государственные органы поддержки инноваций, макроэкономическая политика и законодательство страны, высокотехнологичные производства, рынок новых технологий и инновационных товаров, институты финансовой поддержки новшеств и др. Между этими элементами установлена взаимозависимость и существует взаимовлияние. Схема НИС представлена на рис. 1.

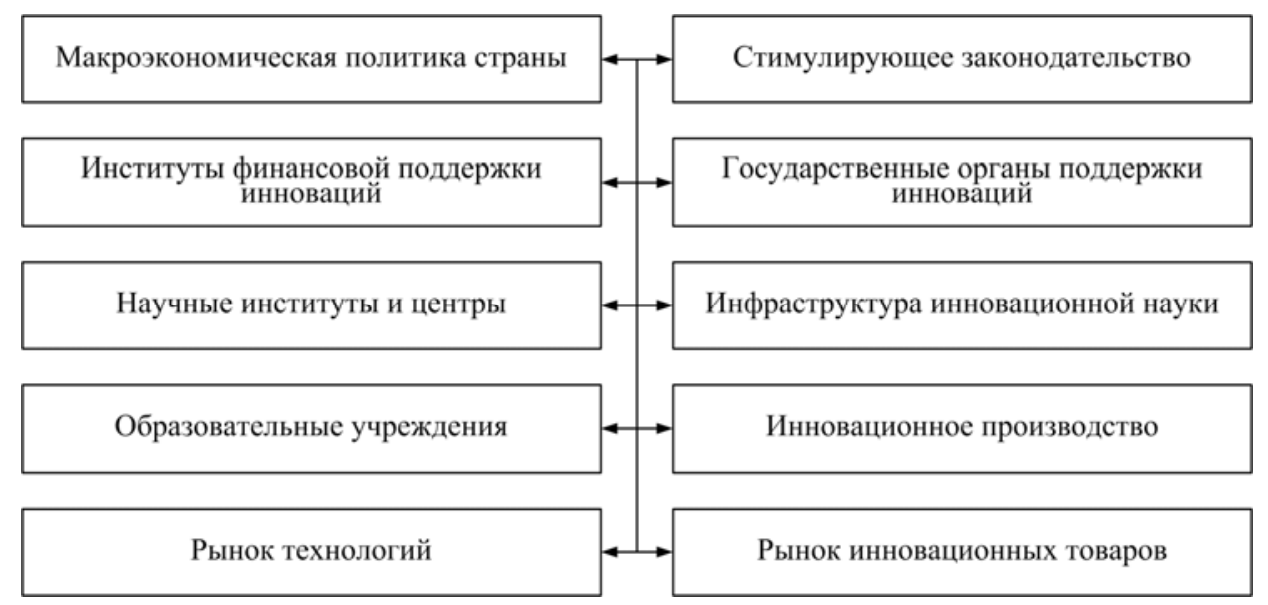

Рис. 1. Схема НИС

НИС создает новое качество, которое не имеется ни у одного из ее элементов: новые технологии, наукоемкое высокотехнологичное производство, инновационные товары, новые профессии - инновационных специалистов и менеджеров, новую специальную психологию и инновационный климат. НИС выполняет в пределах государства роль связующего звена между макроэкономической политикой, наукой, образованием, наукоемкой промышленностью и рынком. Все эти элементы находятся в действии, обладают взаимовлиянием и чувствительностью к внешним воздействиям, между ними устанавливаются функциональные связи. Исключение любого элемента сис- 
темы приводит к разрыву инновационного процесса и тем самым делает невозможным функционирование системы в принципе.

На основании изложенного дадим свое определение НИС.

Национальная инновационная система - это совокупность взаимосвязанных институтов и явлений в рамках государства, способствующих разработке, распространению и внедрению научных достижений в экономику и сочииальную жизнь.

Совокупность элементов является базой системы. Разные авторы включают в состав НИС различные элементы.

Так, В.Н. Шимов и Л.М. Крюков в белорусской инновационной системе выделяют четыре основные группы элементов:

- производственные предприятия, их технологический уровень, конкурентоспособность продукции, позиция на рынке, возрастающий спрос на знания;

- университеты и иные образовательные учреждения, осуществляющие подготовку и переподготовку кадров;

- НИИ и конструкторские бюро, технопарки и бизнес-инкубаторы, консалтинговые фирмы и инновационные базы, внедренческие фонды и лизинговые фирмы;

- территории с высокой концентрацией научно-технического потенциала, технополисы, особые экономические зоны и др. [5. С. 21-22].

НИС призвана выполнять свои специфические функции в экономике и социуме государства. Можно выделить восемь основных функций:

1. Способствование экономическому росту. Эту функцию НИС должна выполнять за счет активного использования интеллектуального потенциала граждан. Интеллект должен быть поэтапно направлен на разные объекты. На первом этапе основное внимание следует уделять новшествам в научнотехнической сфере и производстве наукоемкой продукции, росту конкурентоспособности, особенно на внутреннем рынке. На втором этапе необходимо направить интеллект на вопросы экологии, на создание «зеленой экономики», на образование и медицину, на активный выход на международный рынок за счет повышения конкурентоспособности национальной экономики и государства в целом. На третьем этапе за счет «экономики знаний» следует в центр деятельности НИС поставить вопросы социального развития и повышения качества жизни граждан.

2. Способствование сбалансированному развитию. НИС призвана последовательно поддерживать научный, образовательный и высокотехнологичный сектора экономики, которые, в свою очередь, должны обеспечить получение, распространение и внедрение научно-технологических достижений новых технологий, производство инновационной продукции.

3. Наполнение внутреннего рынка наукоемкой продукцией. Это будет способствовать созданию и поддержанию положительного сальдо во внешнеэкономической деятельности государства. Кроме того, граждане, наряду с государством и крупными негосударственными структурами, будут выступать стратегическими инвесторами в научных исследованиях и высокотехнологичном производстве. 
4. Достижение внутренней устойчивости. НИС способна устойчиво функционировать не только в стабильной экономической и социальной среде, но и в условиях определенной дестабилизации экономической ситуации. Для этого инновационная система должна опираться на собственные ресурсы от коммерческой деятельности и поддержку со стороны государства. Эта поддержка должна выражаться как в правовом поле, так и в материальнофинансовых ресурсах. Если государство не может выделить необходимые финансы, оно может оказать поддержку налоговыми и кредитными льготами, созданием технопарков и другими мерами.

Устойчивость НИС определяется ее особенностью решать стоящие перед ней задачи в настоящем и прогнозируемом будущем, независимо от неблагоприятных изменений окружающей среды. Внедрение инноваций в экономику может происходить даже в условиях кризиса.

5. Стимулирование инноваций. НИС должна способствовать созданию и функционированию организационно-экономических механизмов, направленных на развитие инновационных предприятий, работающих в области коммерциализации научно-технических достижений. Стимулом для развития высокотехнологичных производств может стать их поддержка на уровне государственных и финансовых институтов, венчурного бизнеса, которые обеспечили бы быструю окупаемость и опережающую доходность такого бизнеса.

6. Развитие инновационной инфраструктуры. К инновационной инфраструктуре, согласно рекомендациям ЮНЕСКО, могут быть отнесены учреждения, которые осуществляют определенные виды новаторской деятельности. Основные элементы инновационной инфраструктуры таковы: институты и научные центры, создающие научно-технические разработки; центры хранения и распространения научно-технической информации; издательства научно-технической литературы, в том числе Интернет; лаборатории по стандартизации, сертификации; центры геологических изысканий и разведки полезных ископаемых; маркетинговые и экологические службы; патентнолицензионные учреждения; лизинговые фирмы научного оборудования и измерительных приборов; технологические парки и инкубаторы старт-апов; финансовые инновационные фонды; объекты венчурного бизнеса; консультационные инновационные центры и др. [6. С. 138-139].

7. Инновационное развитие территорий. Особенностью инновационной деятельности, прежде всего на начальном этапе, является то, что она развивается преимущественно в столицах и крупных городах с высоким научным потенциалом. НИС должна способствовать распространению инноваций на всей территории страны, что станет важным фактором их системности.

8. Интегрирование НИС. Инновационные системы состоят из нескольких уровней, в зависимости от охвата территорий: микро - отдельное предприятие, мезо - группа предприятий; макро - в пределах одного государства, гипер - в масштабах мировой экономики. НИС должна обладать способностью эффективно влиять на более низкие уровни и успешно интегрироваться в системы более высокого уровня, поскольку в противном случае она будет отрезана от внешних рынков и ресурсов, в первую очередь научных, технологических и финансовых. 
Выводы

1. Разработка теоретических основ национальных инновационных систем началась с середины 1980-х гг. Первыми исследователями НИС стали К. Фримен, Б.-А. Лундвалл и Р. Нельсон.

2. На основании анализа становления НИС были установлены три методологических принципа: конкуренция производства на основе инноваций есть главный фактор экономического развития; на содержание инновационной деятельности активно влияют организационные институты; новое знание играет особую роль в экономическом развитии.

3.Категория НИС в экономической литературе трактуется по-разному. В связи с этим дано авторское определение: НИС - это совокупность взаимосвязанных институтов и явлений в рамках государства, способствующих разработке, распространению и внедрению научных достижений в экономику и социальную жизнь.

4.Основными функциями НИС являются: способствование экономическому росту, помощь сбалансированному развитию, наполнение внутреннего рынка наукоемкой продукцией; достижение внутренней устойчивости системы, стимулирование собственно инноваций; развитие инновационной инфраструктуры, инновационное развитие территорий, интегрирование НИС с более высокими системами.

\section{Лumepamypa}

1. Васин В.А., Миндели Л.Э. Национальная инновационная система: предпосылки и механизмы функционирования. М.: ЦИСН, 2002. 1993.

2. Глазьев С.Ю. Теория долгосрочного технико-экономического развития. М.: Владар,

3. Иванов В.В. Национальные инновационные системы: теория и практика формирования. М.: Абелия, 2004.

4. Иванова Н.И. Формирование и эволюция национальных инновационных систем. М.: ИМЭМО РАН, 2001.

5. Шимов В.Н., Крюков Л.М. Инновационное развитие экономики Беларуси: движущие силы и национальные приоритеты. Минск: БГЭУ, 2014.

6. Шумилин А.Г. Национальная инновационная система Республики Беларусь. Минск: Акад. упр. при Президенте Респ. Беларусь, 2014.

7. Managing National Innovation Systems. OECD, 1999.

A.G. Shumilin. State Committee on Science and Technology of the Republic of Belarus, Minsk. E-mail: Shlychkova@gknt.org.by

THE ESSENCE AND THE FUNCTION OF THE NATIONAL INNOVATION SYSTEM

Keywords: national innovation system, system functions, system elements, the development, the market.

The article discusses the development of methodological foundations of the "national innovation system" (NIS). In contains also a critical analysis of the views to its essence of the American, British, Swedish, Russian and Belarusian scientists and the author's interpretation of this category. The article examines the relationship and interaction between elements of the NIS. 3 methodological functions have been found out on the basis of the analysis of the NIS. The article proposes the author's approach to the definition of the functions of the NIS and discusses eight major functions of the system. 


\section{References}

1. Vasin V. A., Mindeli L. E. Natsionalhnaya innovatsionnaya sistema: predposylki i mekhanizmy funktsionirovaniya [National Innovation System: Prerequisites and Mechanisms of Functioning]. Moscow, TSISN, 2002.

2. Glazyev S. Y. Teoria dolgosrochnogo tekhniko-ekonomitcheskogo razvitiya [The Theory of Long-Term Technical and Economic Development]. Moscow, Vladar, 1993.

3. Ivanov V. V. Natsionalhnaya innovatsionnaya sistema: teoria i praktika formirovania [National Innovation Systems: Theory and Practice of Formation]. Moscow, Abelia, 2004.

4. Ivanova N. I. Formirovaniye i evolutsiya natsionalhnykh innovatsionnyh sistem [The formation and evolution of national innovation systems]. Moscow, IMEMO RAN, 2001.

5. Shimov V. N., Kryukov L. M. Innovatsionnoye razvitiye ekonomiki Belarusi: dvizhushchiye sily i natsionalhniye prioritety [The Innovative Development of the Belarusian Economy: Driving Forces and National Priorities]. Minsk, BGEU, 2014.

6. Shumilin A. G. Natsionalhnaya innovatsionnaya sistema Respubliki Belarus [The National Innovation System of the Republic of Belarus]. Minsk, Akad.upr.pri Prezidente Resp. Belarus, 2014.

7. Managing National Innovation Systems. OECD, 1999. 